\title{
BREVE ANÁLISIS CUANTITATIVO DE LA EMIGRACIÓN GALLEGA A VENEZUELA
}

\section{Brief quantitative analysis of the Galician emigration to Venezuela}

\author{
Xosé Ramón Campos Álvarez \\ Universidad de Vigo
}

Recibido: 29/04/20 Aceptado: 10/06/20

\begin{abstract}
Resumen
En la década de 1950 Venezuela se convirtió por vez primera en un país receptor de emigración masiva procedente de Europa -Italia, Espańa y Portugal, sobre todo-, desplazando a Argentina entre 1954 y 1959 del primer lugar de países americanos destinatarios de emigración espańola y consecuentemente gallega. En el presente trabajo, se pretende exponer y analizar los datos obtenidos a través de diferentes fuentes sobre la importancia de la presencia gallega en el contexto de la emigración espańola a Venezuela, el origen por provincias de los emigrantes, el sexo, la edad y algunas pinceladas sobre el retorno a la comunidad de origen.
\end{abstract}

Palabras Clave

Venezuela, Galicia, Emigración.

\section{Abstract}

In the 1950s, Venezuela became, for the first time, a recipient country of massive emigration from Europe, mainly from Italy, Spain and Portugal. Between 1954 and 1959 Venezuela displaced Argentina for the first place for American countries destined for Spanish and consequently, Galician emigration. The aim of this project is to present and analyze the data obtained through different sources on the importance of Galician presence in the context of Spanish emigration to Venezuela and the origin of the emigrants by provinces, sex, and age as well as some additional details on the return to the native land.

Keywords

Venezuela, Galicia, Emigration. 


\section{La Emigración gallega a Venezuela en el contexto de la emigración española}

Venezuela y Argentina fueron, entre 1946 y 1960, los principales países latinoamericanos receptores de emigrantes europeos, con un saldo total aproximado de 600.000 personas para Argentina y de 500.000 para Venezuela. Si analizamos las Estadísticas de Emigración publicadas por el Ministerio de Trabajo español entre 1950 y 1960 (Cuadro 1), podemos constatar que Argentina recibió un mayor número de emigrantes españoles en los años que siguieron a la finalización de la II Guerra Mundial, de 1946 a 1953. En el caso de Venezuela, en cambio, se intensificaron los ingresos a partir de 1952 hasta 1958, y desde 1954 sobrepasó a Argentina como el país del continente americano de mayor recepción de inmigrantes españoles, año en el que también se convirtió en el país de mayor recepción de inmigrantes de toda América Latina ${ }^{1}$.

\begin{tabular}{|c|c|c|c|c|c|c|c|c|c|c|c|}
\hline \multicolumn{12}{|c|}{$\begin{array}{l}\text { Cuadro 1. Porcentajes de emigración espańola a América según países de destino: } \\
\qquad 1950-1960 .\end{array}$} \\
\hline & 1950 & 1951 & 1952 & 1953 & 1954 & 1955 & 1956 & 1957 & 1958 & 1959 & 1960 \\
\hline ARGENTINA & 70,1 & 56,7 & 45,0 & 30,4 & 24,0 & 21,7 & 16,1 & 19,6 & 22,7 & 18,8 & 17,6 \\
\hline BRASIL & 5,9 & 13,3 & 25,4 & 26,5 & 20,7 & 16,4 & 15,7 & 14,6 & 12,9 & 20,6 & 24,6 \\
\hline CUBA & 3,3 & 3,5 & 3,0 & 3,3 & 1,7 & 1,8 & 2,0 & 1,8 & 2,1 & 1,8 & 1,1 \\
\hline EE.UU & 0,2 & 0,2 & 0,3 & 0,3 & 0,4 & 0,3 & 0,4 & 0,4 & 0,8 & 0,9 & 1,4 \\
\hline MÉXICO & 1,0 & 1,1 & 1,3 & 0,9 & 0,8 & 0,6 & 0,8 & 0,6 & 1,6 & 1,2 & 1,3 \\
\hline URUGUAY & 2,9 & 4,8 & 8,3 & 8,7 & 7,3 & 9,7 & 9,1 & 8,0 & 6,4 & 5,4 & 3,8 \\
\hline VENEZUELA & 15,0 & 19,0 & 15,4 & 27,6 & 42,0 & 42,2 & 51,9 & 52,1 & 50,5 & 46,9 & 44,7 \\
\hline Otros PAISES & 1,6 & 1,5 & 1,4 & 2,2 & 3,1 & 7,2 & 4,1 & 2,9 & 3,1 & 4,5 & 5,5 \\
\hline
\end{tabular}

Fuente: Estadísticas de Emigración (ańos 1950 a 1960), Ministerio de Trabajo. (Elaboración propia).

1 Para este estudio cuantitativo de la emigración gallega a Venezuela han sido utilizadas las Estadísticas de Emigración publicadas por el Ministerio de Trabajo entre 1946 y 1990, además de una serie de datos, elaborados por Sánchez López (1967) para los años 1957-62, a partir de las Estadísticas del Movimiento de Buques y Pasajeros por Mar con el Exterior del I.N.E. y se han complementado (en aquellos aspectos que no había información) con un muestreo realizado por el autor a partir de casi dos mil inscritos (1837 en total) en los libros del Consulado General de España en Caracas. Registro de Nacionalidad, entre 1950 y 1957. También se han utilizado los datos aportados por las estadísticas venezolanas de Entradas y Salidas de Extranjeros, además de las obras de Susan Berglund y Hernández Calimán (1977 y 1985) y Adela Pellegrino (1989). 
La emigración española a Venezuela aumentó progresivamente en los años cincuenta, constituyendo el 42\% del total a América en 1954 y 1955 y situándose por encima del 50\% en los años 1956, 1957 y 1958 (Cuadro 1). El número más alto de entradas se observa en el año 1957, cuando 30.184 españoles llegaron al país. En los años siguientes la cifra disminuyó paulatinamente (Cuadro 2).

\begin{tabular}{|c|c|c|c|}
\hline \multicolumn{4}{|c|}{ Cuadro 2. Emigración española a Venezuela: 1951-1960. } \\
\hline Año & Venezuela & Total a América & \% a Venezuela \\
\hline 1951 & 10.810 & 56.967 & 18,98 \\
\hline 1952 & 8.734 & 56.648 & 15,42 \\
\hline 1953 & 12.306 & 44.572 & 27,61 \\
\hline 1954 & 22.033 & 52.418 & 42,03 \\
\hline 1955 & 26.277 & 62.237 & 42,22 \\
\hline 1956 & 27.542 & 53.082 & 51,89 \\
\hline 1957 & 30.184 & 57.900 & 52,13 \\
\hline 1958 & 23.811 & 47.179 & 50,47 \\
\hline 1959 & 16.235 & 34.648 & 46,86 \\
\hline 1960 & 14.991 & 33.529 & 44,71 \\
\hline Total & 192.923 & 499.180 & 38,64 \\
\hline
\end{tabular}

Fuente: Estadísticas de Emigración (ańos 1946 a 1960), Ministerio de Trabajo. (Elaboración propia).

Si se analizan las cifras de entradas de emigrantes españoles registradas en las estadísticas venezolanas, puede observarse que no coinciden con las de salida de España con destino a Venezuela reflejadas en las estadísticas españolas (Estadísticas de Emigración del Ministerio de Trabajo) (Cuadro 3), siendo superiores las venezolanas en un 20\% o 25\% anual (1951-1960: 192.923 salidas de España frente a 242.085 entradas de españoles en Venezuela: 20,3\% de diferencia). Esta disparidad se debe a que los registros venezolanos incluyen a aquellos que llegaron a través de los puertos de otros países europeos o americanos, a los que salieron de manera clandestina de España, a los funcionarios, turistas, hombres de negocios, etc. y a la aparición de ciertas duplicidades (aquellos que entraron, salieron del país y volvieron a entrar quedaron contabilizados más de una vez).

Este hecho también se puede apreciar en los datos aportados por Sánchez López (1967: 66-67) sobre el total de españoles que emigraron a Venezuela entre 1957 y 1962, que según este autor fue de 112.607, mientras que las Estadísticas del Ministerio de Trabajo (Cuadro 5) para el mismo periodo arrojan una cifra de 108.117 
emigrantes, lo que supone un $4 \%$ menos, no siendo en este caso muy significativo. Sin embargo, las estadísticas venezolanas que pudimos analizar (Valecillos: 1993, vol.I), reflejan la entrada en el país de 145.201 españoles (un 22,5\% más que la Estadística de Tráfico Marítimo, Buques y Pasajeros manejada por Sánchez López y un 25,5\% más que las Estadísticas de Emigración del Ministerio de Trabajo).

\begin{tabular}{|c|c|c|c|}
\hline \multicolumn{4}{|c|}{ Cuadro 3. Venezuela. Entradas y salidas de espańoles: 1951-1960. } \\
\hline Años & Entradas & Salidas & Saldo \\
\hline 1951 & 12.741 & 3.765 & 8.976 \\
\hline 1952 & 11.799 & 5.134 & 6.665 \\
\hline 1953 & 16.611 & 5.713 & 10.898 \\
\hline 1954 & 24.387 & 6.367 & 18.020 \\
\hline 1955 & 33.025 & 8.693 & 24.332 \\
\hline 1956 & 32.763 & 10.507 & 22.256 \\
\hline 1957 & 35.052 & 12.928 & 22.124 \\
\hline 1958 & 29.204 & 18.283 & 10.921 \\
\hline 1959 & 23.508 & 16.185 & 7.323 \\
\hline 1960 & 22.995 & 21.662 & 1.333 \\
\hline Total & 242.085 & 109.237 & 132.848 \\
\hline
\end{tabular}

Fuente: Valecillos (1993, vol. I). (Elaboración propia).

Según estimaciones de Susan Berglund y Hernández Calimán (1985: 48), durante el periodo comprendido entre 1948 y 1963 llegaron a Venezuela 1.753 .632 inmigrantes y salieron 1.249 .607 , permaneciendo en el país un efectivo de 504.024 personas. El aumento fue paulatino hasta 1957, cuando con 150.361 entradas de extranjeros alcanzó su punto más alto, a partir del cual comenzó a decrecer, siendo los saldos negativos desde 1960, cuando se pusieron trabas legales a la entrada de inmigrantes.

Como se puede constatar a través de los datos anteriores, Venezuela, en la década de 1950, se convirtió en un país receptor de inmigración, produciéndose una llegada masiva de emigrantes debido a la profunda transformación económica que estaba experimentando -impulsada por los beneficios de la explotación del petróleo ${ }^{2}-$ y a la política inmigratoria de "puertas abiertas" del gobierno del dictador

2 Desde 1945 y hasta 1960 Venezuela ocupó el primer lugar del mundo en exportación de petróleo y el segundo en producción, lo que llevó consigo un crecimiento considerable de los ingresos 
Marcos Pérez Jiménez (1952-1958), que ordenó a su director de inmigración "abra usted las puertas de la República a todo europeo que reúna las condiciones convenientes a su juicio" (Troconis, 1986: 275). En este sentido, en los años de 1954 y 1955 se emitieron dos circulares que permitían la entrada como transeúnte a toda persona de origen español, italiano o portugués, que cumpliera solamente tres requisitos: ser menor de 35 años, no tener antecedentes penales y tener un certificado de buena salud. Además, se autorizó a los consulados venezolanos a otorgar visas sin necesidad de consultarlo con el Ministerio de Relaciones interiores. Por tanto, a partir de ese momento, la mayoría de los inmigrantes entraron en el país prácticamente sin restricción alguna.

Se pensaba que se ahorraría tiempo y dinero importando mano de obra que contribuyera al desarrollo del país, ya que formar a los trabajadores venezolanos sería un proceso lento y costoso. Pero la inmigración en Venezuela, salvo algunos casos excepcionales, nunca se caracterizó por ser dirigida. Alrededor del 90\% de los extranjeros que llegaron entre 1937 y 1961 lo hicieron con visa de transeúnte ${ }^{3}$ y desde 1963 todos entraron así, debido a que ya no se expedía la visa de inmigrante. Hecho que confirman las estadísticas del Ministerio de Fomento de Venezuela para el año 1956, que reflejan la llegada de 32.187 españoles (un 14,4\% más que las salidas registradas por las estadísticas españolas que contabilizan 27.542 personas): el $72 \%$ como transeúntes, el $23 \%$ como residentes y sólo el 5\% como inmigrantes. Las salidas fueron de 10.101, proporcionando un saldo total de 22.086 españoles:

(...) el número total de 32.187 (...) debe descomponerse en los siguientes grupos: 22.000 [en números redondos] que permanecen en Venezuela; 5.000 regresados a España; y otros 5.000 que es el movimiento de viajeros -que pudiéramos llamar normal- dado por gente que ya está establecida en Venezuela ${ }^{4}$.

del Estado. Entre 1945 y 1949, el 93 \% del valor total de las exportaciones correspondían al petróleo, y solo el $5 \%$ a la exportación de mineral de hierro y el $2 \%$ a la de café, cacao y otros productos. Posteriormente, Rómulo Betancourt diría que la riqueza que por aquellos años (1948-1958) inundaba la economía venezolana no se empleó coherentemente, ya que se descuidó la agricultura, la ganadería, la sanidad y la cultura, además de otros aspectos de la economía. Tampoco se formuló una política industrial que permitiera al país la posibilidad de alcanzar un desarrollo independiente. El Estado y los sectores dominantes promovieron una cuantiosa e irracional importación de bienes de consumo, en gran parte suntuarios, por lo que los ingresos percibidos por el país a través del petróleo retornaban al exterior como pago de esas importaciones (Fernández Morales, 1992: 53-54).

3 "La revisión de los prontuarios de extranjeros que entraron al país durante la década del cincuenta demuestra que la gran mayoría efectuó su entrada como transeúnte” (Berglund y Hernández Calimán, 1985: 36).

4 AMAE, R-5692, Exp. 6. Informe de la Embajada de España al Ministro de Asuntos Exteriores sobre llegadas y salidas de españoles a Venezuela durante el año 1956. Caracas, 7 de noviembre de 1957. 
En alguna circular también se estableció que los aspirantes debían en principio saber leer y escribir, pero los consulados venezolanos en el extranjero se dieron cuenta de que perderían inmigrantes deseables si insistían en el cumplimiento de esta norma. El único requerimiento estricto era tener buena salud para incorporarse activamente al mercado de trabajo. De esta manera entraron en la década de los cincuenta la mayoría de europeos, siendo los españoles los que tuvieron una presencia mayor, seguido muy de cerca por los italianos, mientras que los portugueses formaban un grupo bastante más pequeño que los anteriores.

Al revisar el censo de la población europea residente en Venezuela en 1950, apreciamos que el número de italianos 43.938 superaba al de españoles que en ese momento era de 37.887. Pero ya en 1955 (Cuadro 4) el porcentaje de españoles era el más alto con un $37,2 \%$, seguido de los italianos con 34,3\%. En 1958, los españoles alcanzaron $41,2 \%$ mientras que los italianos representaban ya solo un $16,2 \%$. Para 1961, los europeos constituían todavía el 68,2\% del total de inmigrantes en el país y los españoles eran la corriente más numerosa, pero ya "solo" representaban el 26,1\% del total (frente al 41,3\% de 1958), seguidos de los italianos con 18,3\% (los portugueses, por su parte, alcanzaron su punto más alto en 1955 con el 12,2\%).

\begin{tabular}{|c|c|c|c|c|c|}
\hline \multicolumn{6}{|c|}{ Cuadro 4. Venezuela. Inmigración por nacionalidad: (1948-1951 -1955-1958 -1961) (\%). } \\
\hline NACIONALIDAD & 1948 & 1951 & 1955 & 1958 & 1961 \\
\hline Sin Nacionalidad & 1,9 & $*$ & $*$ & $*$ & $*$ \\
\hline Alemanes & 1 & 2,7 & 1,9 & 1,4 & 1,7 \\
\hline Argentinos & $*$ & $*$ & 1,4 & 1,3 & 1,2 \\
\hline Colombianos & 4,9 & 4,2 & 1,3 & 7,6 & 12,8 \\
\hline Costarricenses & 1,3 & $*$ & $*$ & $*$ & $*$ \\
\hline Cubanos & 4 & $*$ & $*$ & 2.6 & 13,2 \\
\hline Espańoles & 16 & 33.4 & 37,2 & 41.3 & 26,1 \\
\hline Estadounidenses & 12,8 & 6 & 3,1 & 6,8 & 5,5 \\
\hline Franceses & 3,3 & 1,8 & $*$ & $*$ & $*$ \\
\hline Británicos & 3,3 & 1,8 & $*$ & 1,3 & $*$ \\
\hline Holandeses & 1,3 & $*$ & $*$ & $*$ & $*$ \\
\hline Húngaros & 1,4 & $*$ & $*$ & $*$ & $*$ \\
\hline Italianos & 27,5 & 35,5 & 34,3 & 16,2 & 18,3 \\
\hline Libaneses & $*$ & $*$ & 1,5 & 1 & 1,6 \\
\hline Lituanos & 1 & $*$ & $*$ & $*$ & $*$ \\
\hline
\end{tabular}




\begin{tabular}{|c|c|c|c|c|c|}
\hline NACIONALIDAD & 1948 & 1951 & 1955 & 1958 & 1961 \\
\hline Polacos & 5,4 & $*$ & $*$ & $*$ & $*$ \\
\hline Portugueses & 4,4 & 5,5 & 12,2 & 9 & 9 \\
\hline Rusos & 1,3 & $*$ & $*$ & $*$ & $*$ \\
\hline Sirios & $*$ & $*$ & $*$ & 2 & 2,4 \\
\hline Otros & 9,2 & 9,1 & 7,1 & 9,5 & 8,2 \\
\hline
\end{tabular}

Fuente: Berglund, Susan y Hernández Calimán, Humberto (1985: 49).

Las Estadísticas de Emigración Española publicadas por el Ministerio de Trabajo, reflejan que entre 1948 y 1961 llegaron 216.107 españoles a Venezuela (Cuadro 19). "Una tercera parte de ellos eran oriundos de las Islas Canarias y otro tercio de las provincias de Galicia” (Berglund y Hernández Calimán, 1986: 50). Desde ese último año y hasta 1965 siguió habiendo una afluencia significativa de entradas, pero eran más los que retornaban que los que llegaban, tanto a nivel general como a nivel gallego. Ello se debió, a que una vez derrocado Pérez Jiménez estalló un clima de rechazo contra los extranjeros. Se produjeron algunas demostraciones de xenofobia, sobre todo contra los italianos ${ }^{5}$. Además, a esta situación de inseguridad hay que añadir una coyuntura económica recesiva ${ }^{6}$ - descenso de las rentas del petróleo, aumento del número de parados, huelgas o devaluación de la moneda-, por lo que el nuevo gobierno restringió la inmigración, permitiendo solamente la reagrupación familiar - entrada de familiares inmediatos: cónyuge, hijos y padres de los ya residentes en Venezuela-.

Por disposición de la Junta de Gobierno, este Despacho ha impartido instrucciones a fin de que instruyan a los funcionarios del Servicio Consular para que se abstengan de conceder, hasta nuevo aviso, 'visto bueno' de ingreso a los extranjeros que deseen trasladarse a Venezuela con el propósito de radicarse en el país, con excepción de cónyuge, hijos y padres de los ya residenciados en Venezuela ${ }^{7}$.

5 Los italianos fueron identificados por el pueblo venezolano como "perezjimenistas" por su vinculación con el régimen, sobre todo por su implicación en la construcción de las grandes obras públicas, en las que muchos de los promotores, capataces y obreros fueron italianos. “(...) Muchos de ellos se repatriaron, porque la facilidad de hacer dinero no era la misma; o emigraron a otros países, ya que se desató un cierto ambiente de xenofobia hacia todos los extranjeros, pero principalmente hacia los italianos" (Troconis, 1986: 208).

6 “(...) con el descenso de las rentas del petróleo, aumento del número de parados, huelgas en el sector industrial, devaluación de la moneda (36\% en 1964), disturbios políticos (aparición de guerrillas urbanas)...” (Hernández Borge, 1992: 647-648).

7 Oficio (18 de julio de 1958) incluído en la Memoria y Cuenta del Ministerio de Relaciones Interiores del año 1958. 
Quedó así anulada la política inmigratoria de puertas abiertas. Ante estas circunstancias, muchos inmigrantes abandonaron Venezuela y la corriente migratoria gallega y española en general, a partir de 1959, se reorientó hacia Europa. En el Cuadro 4 se puede apreciar como en 1961 el saldo migratorio de españoles había descendido considerablemente.

Entre 1961 y 1985 salieron de España como emigrantes con destino a Venezuela 95.152 españoles, de los cuales el 57\% (54.387) lo hizo en los cinco años que van de 1961 a 1965, ya que, como podemos observar entre 1965 y 1990, solamente 40.940 españoles se dirigieron al país sudamericano, siendo los canarios el grupo más numeroso con el 48,40\%, seguido de los gallegos con el 37,08\%. Esta emigración de los años sesenta varió sustancialmente en su composición, hasta el punto en que llegaron a predominar las mujeres frente al mayor porcentaje de hombres de la década anterior.

\begin{tabular}{|c|c|c|c|}
\hline \multicolumn{4}{|c|}{ Cuadro 5. Emigración española a Venezuela: 1960-1985. } \\
\hline Año & $\begin{array}{c}\text { No Emigrantes a } \\
\text { Venezuela }\end{array}$ & $\begin{array}{c}\text { \% a Venezuela del total a } \\
\text { América }\end{array}$ & Total a América \\
\hline 1961 & 11.828 & 33,17 & 35.658 \\
\hline 1962 & 11.068 & 34,71 & 31.891 \\
\hline 1963 & 9.774 & 40,03 & 24.416 \\
\hline 1964 & 12.547 & 50,68 & 23.915 \\
\hline 1965 & 9.170 & 44,18 & 20.754 \\
\hline 1966 & 7.713 & 37,24 & 20.710 \\
\hline 1967 & 6.755 & 35,83 & 18.854 \\
\hline 1968 & 4.108 & 39,25 & 10.467 \\
\hline 1969 & 3.722 & 36,75 & 10.129 \\
\hline 1970 & 3.010 & 43,49 & 6.921 \\
\hline 1971 & 2.756 & 45,61 & 6.042 \\
\hline 1972 & 2.220 & 42,59 & 5.213 \\
\hline 1973 & 1.291 & 34,34 & 3.759 \\
\hline 1974 & 1.139 & 36,15 & 3.151 \\
\hline 1975 & 1.447 & 43,56 & 3.322 \\
\hline 1976 & 1.306 & 43,33 & 3.014 \\
\hline 1977 & 1.474 & 51,88 & 2.841 \\
\hline 1978 & 1.277 & 59,07 & 2.162 \\
\hline 1979 & 1.043 & 52,54 & 1.985 \\
\hline 1980 & 417 & 30,40 & 1716 \\
\hline 1981 & 420 & 24,48 & \\
\hline & & & \\
\hline
\end{tabular}




\begin{tabular}{|c|c|c|c|}
\hline Ańo & $\begin{array}{c}\text { NoEmigrantes a } \\
\text { Venezuela }\end{array}$ & $\begin{array}{c}\text { \% a Venezuela del total a } \\
\text { América }\end{array}$ & Total a América \\
\hline 1982 & 357 & 23,42 & 1524 \\
\hline 1983 & 168 & 13,77 & 1220 \\
\hline 1984 & 90 & 8,20 & 1097 \\
\hline 1985 & 52 & 5,31 & 979 \\
\hline $1961-1985$ & 95.152 & 39,14 & 243.112 \\
\hline
\end{tabular}

Fuente: Estadísticas de Emigración (años 1960 a 1985), Ministerio de Trabajo. (Elaboración propia).

En el Cuadro 6 podemos apreciar, tal y como se ha venido diciendo en este estudio, que casi dos tercios de los españoles que emigraron a Venezuela entre 1946 y 1985 lo hicieron en la década de los cincuenta (Ver también Cuadro 19). Las entradas disminuyeron considerablemente en la siguiente década, ya que los aportes estaban en función, sobre todo, de la inercia dada a través de las llegadas por reagrupación familiar. Entre 1961 y 1971 la colonia española perdió 20.000 efectivos, al pasar de contar con 166.660 en 1961 a 149.747 diez años después.

\begin{tabular}{|c|c|c|}
\hline \multicolumn{3}{|c|}{ Cuadro 6. Emigración espańola a Venezuela por décadas: 1946-1980. } \\
\hline Años & Venezuela & Total América \\
\hline $1946-1950$ & 12.156 & 135.487 \\
\hline $1951-1960$ & 192.902 & 500.491 \\
\hline $1961-1970$ & 86.648 & 240.627 \\
\hline $1971-1980$ & 14.370 & 44.506 \\
\hline $1946-1980$ & 306.076 & 921.111 \\
\hline
\end{tabular}

Fuente: Estadísticas del Instituto Español de Emigración.

En la década de los setenta y principios de los ochenta se confirmó la tendencia a la baja del flujo migratorio a América Latina: de los alrededor de 5.000 emigrantes españoles asistidos registrados en 1970 se pasó a unos 1.000 en 1980, manteniéndose en los años siguientes esta evolución. Venezuela siguió siendo el destino preferido de esta corriente migratoria, al recibir casi la mitad del total de emigrantes del periodo comprendido entre 1970 y 1980, en su mayoría emigrantes reagrupados; muy por detrás se situó Argentina (12\%), seguida de Brasil, México y Perú, que recibieron en estos años entre el 5 y el 10\% de esta emigración (Fernández Vicente y Kreienbrink, 2009: 232).

En esos años, a pesar de las restricciones impuestas desde el inicio del período democrático, para todo aquel que quisiera emigrar a Venezuela era sumamente 
sencillo llegar al país como turista y arreglar posteriormente los papeles necesarios para obtener un visado de transeúnte primero y de residente después; así entró la mayoría de los gallegos hasta finales de 1980. Es evidente que muchos de estos emigrantes no quedaron registrados en las Estadísticas de Emigración del Ministerio de Trabajo, que no reflejaron el pequeño rebrote que se produjo entre 1973 y 1980, cuando Venezuela volvió a experimentar un importante crecimiento económico. A partir de 1973, la brusca subida de los precios del petróleo proporcionó una época de prosperidad nunca vista hasta entonces, que coincidió con la nacionalización de la industria petrolífera en 1976 por parte de Carlos Andrés Pérez (AD). El presupuesto nacional se triplicó en un sólo año, lo que llevó consigo el desarrollo de diferentes programas económicos con fuertes inversiones de capital y la creación de puestos de trabajo, muchos de ellos ocupados por mano de obra extranjera.

El país disfrutó de una relativa tranquilidad, estabilidad política y auge económico. La economía venezolana fue estimulada por las ganancias crecientes relacionadas con el petróleo, lo cual llevó consigo la disminución del desempleo y ocasionó en todos los sectores de la economía una gran demanda de trabajadores. Venezuela se convirtió de nuevo en "tierra de promisión" y volvió a experimentar una corriente inmigratoria de carácter espontáneo y masivo. Colombianos -sobre todo-y portugueses - en mucha menor medida- fueron las nacionalidades predominantes, pero se aprecia una creciente inmigración de otros países latinoamericanos. Éstos representaron la mitad o más de la inmigración sustituyendo a los europeos y convirtiéndose el colectivo colombiano en la comunidad de extranjeros más numerosa. Se trata de nuevo de una inmigración no seleccionada, ni canalizada, ni controlada por el Estado venezolano (Berglund y Hernández Calimán, 1985: 60-61).

En 1981, según datos obtenidos de la DIEX (Dirección de Identificación y Extranjería), los extranjeros residentes en Venezuela según la nacionalidad de origen se distribuían de la siguiente manera: 594.016 colombianos; 277.513 españoles; 210.980 italianos; 137.878 portugueses; 28.786 chilenos; 28.487 ecuatorianos; 25.433 peruanos; 24.824 cubanos; 21.553 dominicanos; 19.544 argentinos, etc. Destacaba el elevado número de colombianos, casi la mitad en situación ilegal, lo cual se puede hacer extensivo al resto de inmigrantes latinoamericanos (excepto los procedentes de Chile, Argentina y Cuba).

La débil emigración gallega que había ido llegando en la década de los sesenta lo había hecho a través de la política inmigratoria de reagrupación familiar y con el apoyo de la CCEM (Comisión Católica Española de Migración). Según Ramón Contiña (1982) y Hernández Arvelo (1990: 106) la nueva presencia de gallegos en Venezuela, si bien tuvo un "significativo repunte" entre 1975 y 1980, "sólo llegaba 
a un centenar anual". Lo cierto, es que la cifra de gallegos que salieron de España como emigrantes con destino a Venezuela entre 1971 y 1980, no llega a sobrepasar los cinco mil (4.676 exactamente), lo que supone un 33\% del total de españoles (Cuadro 7). El grupo más numeroso corresponde, como en décadas anteriores, a los canarios con 7.335 efectivos (51,5\%). Sólo se registran 14.273 españoles para toda la década. Sin embargo, según datos de la DIEX venezolana, los españoles cedulados entre 1971 y 1979 sumaron un total de 26.613 personas (Cuadro 8). En cuanto al perfil de estos nuevos inmigrantes, se trataba en su mayoría de profesionales y técnicos cualificados por un lado, y de artesanos y obreros industriales por otro.

\begin{tabular}{|c|c|c|c|c|}
\hline \multicolumn{5}{|c|}{ Cuadro 7. Emigración espańola a Venezuela. Distribución por CC.AA. } \\
\hline CC.AA. & $1965-1970$ & $1971-1980$ & $1981-1990$ & Total \\
\hline Andalucía & 307 & 170 & 54 & 531 \\
\hline Aragón & 300 & 191 & 24 & 515 \\
\hline Asturias & 300 & 191 & 24 & 515 \\
\hline Baleares & 33 & 18 & 0 & 51 \\
\hline Canarias & 12.081 & 7.355 & 382 & 19.818 \\
\hline Cantabria & 153 & 27 & 6 & 186 \\
\hline C. La Mancha & 30 & 34 & 24 & 88 \\
\hline C. León & 174 & 150 & 15 & 339 \\
\hline Cataluńa & 443 & 260 & 107 & 810 \\
\hline C. Valenciana & 161 & 65 & 27 & 253 \\
\hline Extremadura & 12 & 9 & 11 & 32 \\
\hline Galicia & 10.363 & 4.676 & 141 & 15.180 \\
\hline Madrid & 953 & 1.089 & 406 & 2.448 \\
\hline Murcia & 12 & 10 & 2 & 24 \\
\hline Navarra & 52 & 20 & 12 & 84 \\
\hline País Vasco & 19 & 3 & 2 & 24 \\
\hline Rioja, La & 19 & 3 & 2 & 24 \\
\hline Ceuta y Melilla & 16 & 2 & 0 & 18 \\
\hline Total & 25.428 & 14.273 & 1.239 & 40.940 \\
\hline
\end{tabular}

Fuente: Ministerio de Trabajo. Anuario de Migraciones (1992: 76-77). (Elaborado por la Dirección General de Migraciones sobre datos del flujo migratorio en el periodo). (Elaboración propia). 
Cuadro 8. Espańoles cedulados en Venezuela: 1940-1979.

\begin{tabular}{|c|c|c|c|c|}
\hline & $1940-1949$ & $1950-1959$ & $1960-1970$ & $1971-1979$ \\
\hline Espańoles & 14.866 & 168.220 & 67.337 & 26.613 \\
\hline
\end{tabular}

Fuente: DIEX.

Entre 1981 y 1990 hubo un descenso importante en el número de extranjeros europeos, sin duda debido a la crisis económica iniciada con el denominado "viernes negro" (18 de febrero de 1983) que llevó consigo la devaluación de la moneda venezolana, situación que impulsó a muchos inmigrantes de la primera generación a retornar a sus lugares de origen. Esta tendencia se aprecia sobre todo entre españoles, italianos y portugueses (en menor medida), como consecuencia de la creciente inestabilidad económica y política en que se irá sumiendo Venezuela. Los porcentajes de la población española e italiana se redujeron considerablemente desde la década anterior y continuaron disminuyendo en las décadas siguientes (Cuadro 8), al tiempo que se produjo un gran crecimiento de la población de origen colombiano. Entre los años 1981 y 1990, es de destacar la salida de 40.000 españoles, 25.000 portugueses y 20.000 italianos (Cuadro 9).

\begin{tabular}{|c|c|c|c|c|c|c|c|}
\hline \multicolumn{6}{|c|}{ Cuadro 9. Venezuela. Población total según lugar de nacimiento: 1936-1990. } \\
\hline AN̂́ CENSAL & 1936 & 1941 & 1950 & 1961 & 1971 & 1981 & 1990 \\
\hline $\begin{array}{c}\text { Total } \\
\text { Venezuela }\end{array}$ & 3.364 .347 & 3.850 .771 & 5.034 .838 & 7.523 .999 & 10.721 .522 & 14.516 .735 & 18.105 .265 \\
\hline $\begin{array}{c}\text { Nacidos } \\
\text { Venezuela }\end{array}$ & 3.317 .321 & 3.800 .843 & 4.828 .071 & 6.982 .436 & 10.125 .067 & 13.442 .106 & 17.082 .006 \\
\hline $\begin{array}{c}\text { Nacidos } \\
\text { Exterior }\end{array}$ & 47.026 & 49.928 & 206.767 & 541.536 & 596.455 & 1.074 .629 & 1.023 .259 \\
\hline $\begin{array}{c}\text { Total } \\
\text { América }\end{array}$ & 30.107 & 23.674 & 76.023 & 152.647 & 231.403 & 667.519 & 686.716 \\
\hline $\begin{array}{c}\text { Colombianos } \\
\text { Total Europa }\end{array}$ & 19.421 & 16.979 & 45.969 & 102.314 & 180.144 & 508.166 & 529.924 \\
\hline Espańoles & 5.746 & 6.959 & 37.887 & 166.660 & 149.747 & 144.405 & 104.037 \\
\hline Italianos & 2.652 & 3.137 & 43.938 & 121.733 & 88.249 & 80.002 & 61.800 \\
\hline Portugueses & 34 & 650 & 10.954 & 41.973 & 60.430 & 93.029 & 68.277 \\
\hline $\begin{array}{c}\text { Total otros } \\
\text { países }\end{array}$ & 1.018 & 1.316 & 3.759 & 16.617 & 26.566 & 59.106 & 80.644 \\
\hline
\end{tabular}

Fuente: Censo General de Población y Vivienda, 1936-1990. 
Por tanto, los saldos migratorios para la década de los setenta que fueran positivos para españoles (4.991), italianos (6.776) y sobre todo portugueses (38.569), en la década siguiente, desde 1980 hasta 1986 (último año del que se dispone de datos), se puede observar una marcada tendencia al retorno, ya que dichos saldos migratorios fueron negativos para españoles (-8.887), italianos (-11.845) e incluso portugueses (-7205) (Cuadro 10).

\begin{tabular}{|c|c|c|c|}
\hline \multicolumn{4}{|c|}{ Cuadro 10. Venezuela. Saldo migratorio espańoles, italianos y portugueses 1971-86 } \\
\hline Año & Españoles & Italianos & Portugueses \\
\hline 1971 & 2116 & 2118 & 3016 \\
\hline 1972 & 901 & -1165 & 2759 \\
\hline 1973 & -953 & 782 & 1132 \\
\hline 1974 & -266 & 682 & 68 \\
\hline 1975 & 2189 & -96 & 4926 \\
\hline 1976 & 3124 & 112 & 2608 \\
\hline 1977 & 1601 & -50 & 1085 \\
\hline 1978 & -4934 & 5165 & 15435 \\
\hline 1979 & 1213 & -772 & 7540 \\
\hline 1980 & -1185 & -1973 & -1031 \\
\hline 1981 & -965 & -3602 & -387 \\
\hline 1982 & -456 & -1987 & 1072 \\
\hline 1983 & 250 & 1039 & -2561 \\
\hline 1984 & -2363 & -1299 & -254 \\
\hline 1985 & -1892 & -951 & -1226 \\
\hline 1986 & -2276 & -3072 & -2818 \\
\hline Total: 1971-1979 & 4991 & 6776 & 38569 \\
\hline Total:1980-1986 & -8887 & -11845 & -7205 \\
\hline Total: 1971-1986 & -3896 & -5069 & 31364 \\
\hline
\end{tabular}

Fuente: Dirección Nacional de Identificación y Extranjería (DIEX).

\section{Lugares de asentamiento de la emigración española en Venezuela}

Sobre el lugar de residencia, en 1951, nueve de cada diez españoles censados en Venezuela estaban asentados en sólo cinco entidades federales (Palazón, 1995a: 
320): en la Capital Federal, Caracas, residía el 69\% (atraída por la gran actividad comercial, financiera e industrial que desarrolla esta ciudad), seguida del Estado Miranda (9\%), Estado Carabobo (4\%) y Estado Aragua (3\%), todos ellos próximos a la capital. En Miranda se estaba expandiendo la industria de la capital y la presencia extranjera iba en aumento. Otras ciudades en proceso de industrialización eran: Valencia y Puerto Cabello en el Estado Carabobo y Maracay en Aragua. El Estado Zulia (3\%), presentaba un destacado proceso industrializador gracias a la explotación del petróleo en el lago Maracaibo, que convirtió a la ciudad en un importante centro industrial y comercial. En 1961, la población española se había cuadruplicado llegando a los 166.660 residentes en Venezuela (uno de cada tres extranjeros y dos de cada cien habitantes de Venezuela eran españoles).

\section{Emigración gallega a Venezuela por provincias ${ }^{8}$}

La llegada de gallegos (al igual que del resto de españoles) a Venezuela hasta 1950 fue insignificante, aumentando considerablemente a partir de 1954. La mitad de todos los españoles llegados a Venezuela lo hizo en los seis años comprendidos entre 1952 y 1958 (150.000 inmigrantes). La emigración gallega a Venezuela fue, dentro de la española, la segunda más numerosa, a poca distancia de la canaria.

Entre 1955 y 1958, una de cada seis personas ceduladas en Venezuela era de origen gallego. En 1961 los españoles sólo representaban un 26,1\% de los extranjeros en Venezuela, sin embargo una tercera parte de ellos eran gallegos (Ramírez Ribes, 2001: 11).

Debido a que las Estadísticas de Emigración Española publicadas por el Ministerio de Trabajo no establecen la relación "provincia de origen-país de destino", se ha tenido que recurrir a los datos elaborados por Sánchez López a partir de la Estadística de Tráfico Marítimo. Buques y pasajeros, para los años 1957-1962 (Cuadro 11). En este periodo la emigración gallega a Venezuela (40.154) supone el 35,66\% de la española (112.607). Por provincias, la de Pontevedra es la más numerosa (36,63\%), seguida de A Coruña con un 29,47\% y de Ourense (26,5\%), quedando la de Lugo a gran distancia $(7,4 \%)$.

8 Las estadísticas de emigración española publicadas por el Ministerio de Trabajo desde 1946 no aportan datos sobre las provincias de origen de los emigrantes y países de destino hasta el año 1967, por tanto, es imposible saber el número exacto de gallegos que emigraron a Venezuela, sus profesiones, sexo, etc. Sí podemos establecer el número de españoles que emigraron a Venezuela, sus profesiones, puertos de salida y bandera de los buques que les llevaron, pero no ofrecen datos del número de hombres, mujeres, estado civil, instrucción y el número de familias, según los países de destino. (En cambio, se dispone de esa información por provincias de procedencia para el total de América). 


\begin{tabular}{|c|c|c|}
\hline \multicolumn{3}{|c|}{$\begin{array}{c}\text { Cuadro 11. Emigración gallega transoceánica por vía marítima a Venezuela, clasificada según } \\
\text { provincia de procedencia: 1957-1962. }\end{array}$} \\
\hline PROVINCIAS & VENEZUELA & $\%$ \\
\hline A Coruña & 11.834 & 29,47 \\
\hline Lugo & 2.973 & 7,4 \\
\hline Ourense & 10.640 & 26,5 \\
\hline Pontevedra & 14.707 & 36,63 \\
\hline Total Gallego & 40.154 & 35,66 \\
\hline Total Nacional & 112.607 & 100 \\
\hline
\end{tabular}

Fuente: Elaboración propia a partir de Sánchez López (1967).

Según Ramón Contiña (1982: 116), que se basa en datos obtenidos por él mismo en la DIEX, entre 1948 y 1961 se cedularon 78.698 gallegos, lo que supondría el $36,42 \%$ del total de españoles llegados a Venezuela. Los inmigrantes cedulados en esos años fueron 612.425, casi todos europeos (Cuadro 12). Las cifras reales es posible que sean ligeramente superiores, ya que junto a trabajadores adultos también llegaron algunos niños, que o no fueron cedulados o lo fueron años más tarde. Si le damos credibilidad a los datos de Contiña, y se le añaden los 15.180 emigrantes gallegos a Venezuela que reflejan las Estadísticas de Emigración del Ministerio de Trabajo por comunidades autónomas para los años 1965 a 1990 (Cuadro 13), se podría establecer que la cifra aproximada de gallegos que llegaron a Venezuela entre 1946 y 1985, periodo objeto de este estudio, rondaría las 100.000 personas.

\begin{tabular}{|c|c|c|c|}
\hline \multicolumn{4}{|c|}{$\begin{array}{c}\text { Cuadro 12. Número aproximado de gallegos cedulados en Venezuela. Porcentaje dentro del } \\
\text { total y total de inmigrantes cedulados entre 1948-1961. }\end{array}$} \\
\hline AN̄O & $\begin{array}{c}\text { \% de gallegos } \\
\text { cedulados }\end{array}$ & $\begin{array}{c}\text { No de gallegos } \\
\text { cedulados }\end{array}$ & $\begin{array}{c}\text { Total de inmigrantes } \\
\text { cedulados }\end{array}$ \\
\hline 1948 & 0,5 & 192 & 38.319 \\
\hline 1949 & 1,43 & 513 & 35.865 \\
\hline 1950 & 2,36 & 948 & 40.150 \\
\hline 1951 & 3,3 & 1.130 & 32.236 \\
\hline 1952 & 7,15 & 2.363 & 33.052 \\
\hline 1953 & 10,97 & 4.910 & 44.756 \\
\hline 1954 & 14,79 & 6.891 & 46.594 \\
\hline 1955 & 18,6 & 13.178 & 75.153 \\
\hline 1956 & 25,4 & 15.307 & 60.311 \\
\hline 1957 & 24,5 & 16.019 & 65.392 \\
\hline
\end{tabular}




\begin{tabular}{|c|c|c|c|}
\hline AÑo & $\begin{array}{c}\text { \% de gallegos } \\
\text { cedulados }\end{array}$ & $\begin{array}{c}\text { No de gallegos } \\
\text { cedulados }\end{array}$ & $\begin{array}{c}\text { Total de inmigrantes } \\
\text { cedulados }\end{array}$ \\
\hline 1958 & 16,1 & 8.591 & 53.361 \\
\hline 1959 & 13,2 & 4.181 & 31.673 \\
\hline 1960 & 10,3 & 2.983 & 28.958 \\
\hline 1961 & 7,3 & 1.492 & 26.599 \\
\hline Total Gallegos & & 78.698 & 612.425 \\
\hline
\end{tabular}

Fuente: Contiña (1982: 117).

Las Estadísticas de Emigración del Ministerio de Trabajo solamente recogen datos de las salidas de españoles con destino a Venezuela por regiones entre 1965 y 1990. En los datos obtenidos de ellas se confirma que los canarios constituyeron el grupo más numeroso de inmigrantes, 19.818, lo que suponía el 48,40\% del total, seguido de los gallegos con 15.180 efectivos, que representaba el 37,08\%. Las demás comunidades presentaban unos porcentajes ínfimos (Cuadro 13).

Cuadro 13. Emigración española a Venezuela por comunidades autónomas: 1965-1990.

\begin{tabular}{|c|c|c|}
\hline C. Autónoma & $1965-1990$ & $\%$ \\
\hline Andalucía & 531 & 1,30 \\
\hline Aragón & 515 & 1,26 \\
\hline Asturias & 515 & 1,26 \\
\hline Baleares & 51 & 0,12 \\
\hline Canarias & 19.818 & 48,40 \\
\hline Cantabria & 186 & 0,45 \\
\hline C. La Mancha & 88 & 0,21 \\
\hline C. León & 339 & 0,83 \\
\hline Cataluña & 810 & 1,98 \\
\hline C. Valenciana & 253 & 0,62 \\
\hline Extremadura & 32 & 0,08 \\
\hline Galicia & 15.180 & 37,08 \\
\hline Madrid & 2.448 & 5,98 \\
\hline Murcia & 24 & 0,06 \\
\hline Navarra & 84 & 0,21 \\
\hline País Vasco & 24 & 0,06 \\
\hline
\end{tabular}




\begin{tabular}{|c|c|c|}
\hline C. Autónoma & $1965-1990$ & $\%$ \\
\hline Rioja, La & 24 & 0,06 \\
\hline Ceuta y Melilla & 18 & 0,04 \\
\hline TOTAL & 40.940 & 100,00 \\
\hline
\end{tabular}

Fuente: Estadísticas de Emigración (años 1965 a 1990), Ministerio de Trabajo. (Elaboración propia).

\section{Emigración gallega a Venezuela según sexo}

En 1950, cuando aún estaba iniciándose este proceso migratorio, de un total de 1.559 españoles ( $85 \%$ de origen gallego) que embarcaron en el puerto de Vigo con destino a La Guaira, 1.343 eran varones (86\%) por tan solo 216 mujeres (14\%) ${ }^{9}$. Porcentajes que indican una presencia masculina muy mayoritaria en los primeros años, pero, la tendencia a lo largo de la década, fue una disminución considerable de la diferencia entre ambos sexos. En 1954, entre los españoles llegados a Venezuela (24.062 según datos de la Dirección de Extranjeros venezolana) todavía el porcentaje de hombres $(65,5 \%)$ era muy superior con respecto a las mujeres $(34,5 \%)$ tal y como se desprende del siguiente informe, en el que se confirma que canarios y gallegos forman el contingente más numeroso y que los porcentajes de repatriación son bastante bajos (2,1\%), indicativo de que la gran mayoría encuentra trabajo y colocación:

Según datos de la Dirección de Extranjeros, donde de una manera rigurosa se registran todos los extranjeros que entran en el país, han llegado a Venezuela en todo el año 1954, los siguientes españoles: Hombres: 15.752 (65,5\%); Mujeres: 8.320 (34,5\%). Lo que hace un total de 24.062 españoles, lo que representa unos 2.000 mensuales. Teniendo en cuenta la Orden Circular (reservada) No 20 del 17 de enero de 1955, en donde se dice que salieron de España en el año 1954, para todo el mundo, 44.572 españoles, tenemos en Venezuela un $53,3 \%$ del total de inmigrantes. Entre los que actualmente llegan a estas costas, el mayor número corresponde a los canarios, después siguen los gallegos y asturianos y etc. etc. Los vascos son los más arraigados que se hallan en el país, los mejor situados y los de mejor posición económica. (...) La realidad es que la mayor parte de los que llegan encuentran trabajo y colocación, pues los que se han repatriado en el año 1954 ascienden a 522, lo que representa un $2,1 \%$, y, de estos, casi todos son los que no tienen preparación técnica o una especialidad; son los que quieren hacer de todo, sea lo que sea, viéndose

9 Arquivo Histórico Provincial de Pontevedra (AHPPO): Documentación Comisaría Cuerpo General de Policía Puerto de Vigo, ano 1950, caixas 17-22. 
obligados a cambiar de empleo, no siendo tenido en cuenta ni apreciado por sus jefes los trabajos que hacen, ya que estos son de fácil sustitución ${ }^{10}$.

En las cifras aportadas por el Censo venezolano de $1961^{11}$, con respecto a la población nacida en el exterior clasificada por países, se puede observar que el 58,62\% de los españoles censados eran hombres y el 41,38\% mujeres (Cuadro 14). Teniendo en cuenta que en la década de los cincuenta entró en el país el 63\% de todos los españoles que emigraron entre 1946 y 1980, estos datos son bastante significativos y dan una idea aproximada de los porcentajes de hombres y mujeres en esta emigración. En el caso de italianos y portugueses, las tasas de masculinidad son mucho más altas: $71,5 \%$ para los primeros y $78,2 \%$ para los segundos.

\begin{tabular}{|c|c|c|}
\hline \multicolumn{2}{|c|}{ Cuadro 14. Venezuela. Población nacida en Europa según sexo. } \\
Muestra del Censo de 1961.
\end{tabular}

Fuente: Anuario Estadístico de Venezuela 1957-1963. (Elaboración propia).

Por tanto, el mayor porcentaje de inmigrantes gallegos y españoles a Venezuela fueron hombres sin apenas especialización, de procedencia rural en una proporción alta, que en su mayoría se establecieron en las ciudades - Caracas sobre todo-, donde realizaron sus primeros trabajos en la construcción como peones o como trabajadores domésticos. En menor medida trabajaron en el comercio como empleados.

Se observa una presencia cada vez más elevada de mujeres casadas, que en algunos casos precedían al marido, ya que no había capacidad económica para sufragar el pasaje de todos los miembros de la familia y era mucho más fácil para las mujeres encontrar trabajo en el servicio doméstico. Además, podían ver las posibilidades de trabajo para el esposo y ahorrar para financiar su viaje. También fueron mujeres solteras jóvenes que contaban con la autorización paterna, deseosas de mejorar su situación y la de su familia. Un hecho destacado fueron los bajos índices de delin-

10 AMAE, R-5692, Exp. 5-6. Informe del Cónsul General de España en Venezuela al Ministro de Asuntos Exteriores con datos e información sobre inmigración y colonia española en Venezuela. Caracas, 29 de julio de 1955.

11 Anuario Estadístico de Venezuela. 1957-1963. República de Venezuela, Ministerio de Fomento, Dirección General de Estadística y Censos Nacionales, Caracas, 1964. 
cuencia entre la colonia española, muy inferior a la de las otras colectividades de extranjeros según un informe de 1959:

Las proporciones entre varones y hembras. El cociente más reducido lo da la colonia española con mucha diferencia sobre la italiana y la portuguesa. Es un buen argumento cerca de estas Autoridades de Inmigración preocupadas por el tema.

Otro buen argumento que cito aquí como curiosidad: el índice de delincuencia, inferior para la colonia española, la más numerosa de las cuatro grandes colonias extranjeras. El orden es así: colombianos, italianos, portugueses y españoles ${ }^{12}$.

En los datos de que se dispone sobre la emigración española a Venezuela, entre 1968 y 1981 (Cuadro 15), se puede apreciar como los porcentajes están invertidos. Las mujeres representaban el 54,64\% y los hombres el 45,36\%, lo cual está en relación con el cierre oficial de la emigración y la política que favoreció la "reagrupación familiar". El porcentaje de mujeres casadas $(55,81 \%)$ fue superior al de las solteras (34,53\%), mientras que en el caso de los hombres eran mayoría los solteros (57,35\%). Destaca también el porcentaje de mujeres viudas (9,66\%) que seguramente irían reclamadas por sus hijos.

\begin{tabular}{|c|c|c|c|c|}
\hline \multicolumn{5}{|c|}{ Cuadro 15. Emigración Espańola a Venezuela según sexo: 1968-1981. } \\
\hline Sexo & Solteros/as & Casados/as & Viudos/as & Total (1968-1981) \\
\hline Hombres & 57,35 & 40,14 & 2,51 & 45,36 \\
\hline Mujeres & 34,53 & 55,81 & 9,66 & 54,64 \\
\hline
\end{tabular}

Fuente: Estadísticas del Instituto Español de Emigración. (Elaboración propia).

Este cambio que se produce en la inmigración hacia un crecimiento de la corriente femenina, que ya se evidencia en 1961, fue resultado, como ya se comentó, de varios factores:

- La estabilidad económica lograda por los varones que habían emigrado anteriormente y luego llevaron a sus familias.

- La política inmigratoria venezolana posterior a julio de 1958, que fomentó la reagrupación familiar.

- La creciente incorporación de la mujer al proceso migratorio.

- El cambio de destino de la emigración española hacia Europa.

12 AMAE, R-5692, Exp. 6. Informe sobre cifras de inmigración en Venezuela. Caracas, 27 de enero de 1959. 


\section{Emigración gallega a Venezuela por edad}

Para este apartado, pueden servir de orientación los datos obtenidos por el autor sobre una muestra de 1.837 españoles inscritos en los Registros de Nacionalidad del Consulado General de España en Caracas entre 1950 y 1957, donde el grupo más numeroso de emigrantes españoles a Venezuela corresponde a personas con una edad comprendida entre los 25 y 34 años (51,59\% de hombres y 36,96\% de mujeres). El 92\% de los inmigrantes tenían una edad comprendida entre los 15 y los 44 años (Cuadro 16).

\begin{tabular}{|c|c|c|}
\hline \multicolumn{3}{|c|}{ Cuadro 16. Emigración española a Venezuela por edad: 1950-1957. } \\
\hline EDAD (1950-1957) & Hombres & Mujeres \\
\hline Hasta 14 ańos & 1,27 & 4,35 \\
\hline de 15 a 24 & 26,11 & 30,43 \\
\hline de 25 a 34 & 51,59 & 36,96 \\
\hline de 35 a 44 & 15,29 & 15,22 \\
\hline de 45 a 54 & 5,1 & 8,69 \\
\hline Más de 55 & 0,64 & 4,35 \\
\hline
\end{tabular}

Fuente: Consulado General de España en Caracas. Registro de Nacionalidad. (Elaboración propia).

Por otra parte, en los datos obtenidos en los listados de embarque a Venezuela desde el puerto de Vigo en 1950, podemos observar que el 76,9\% del total de gallegos que fueron a Venezuela ese año tenían una edad comprendida entre los 16 y los 40 años (Cuadro 17). Siendo similar el porcentaje en el caso de los hombres $(79,2 \%)$ y bajando hasta el $60,7 \%$ en el caso de las mujeres. Como es lógico el grupo más numeroso corresponde a gente joven en edad de trabajar y aportar lo mejor de su esfuerzo en un país, en una sociedad y en un mercado laboral que le son ajenos, pero a donde llegan dispuestos a realizar cualquier actividad necesaria para conseguir mejorar su situación económica.

\begin{tabular}{|c|c|c|c|}
\hline \multicolumn{4}{|c|}{ Cuadro 17. Emigración gallega a Venezuela por edad. Puerto de Vigo 1950} \\
\hline EDAD & \% TOTAL & \% HOMBRES & \% MUJERES \\
\hline $0-15$ & 4,9 & 3,1 & 17,8 \\
\hline $16-30$ & 44,1 & 45,4 & 34,9 \\
\hline $31-40$ & 32,8 & 33,8 & 25,8 \\
\hline $41-50$ & 14,7 & 14,8 & 14,1 \\
\hline
\end{tabular}




\begin{tabular}{|c|c|c|c|}
\hline EDAD & \% TOTAL & \% HOMBRES & \% MUJERES \\
\hline $51-65$ & 3,2 & 2,8 & 6,1 \\
\hline$>66$ & 0,3 & 0,1 & 1,3 \\
\hline Total & 100 & 100 & 100 \\
\hline
\end{tabular}

Fuente: Arquivo Histórico Provincial de Pontevedra (AHPPO). Documentación Comisaría Cuerpo General de Policía Puerto de Vigo, ano 1950, caixas 17-22. Elaboración propia.

\section{Retorno}

Según las estadísticas del Instituto Español de Emigración, entre 1948 y 1958 el número total de españoles que emigraron a Venezuela fue de 173.053 y el de retornados de este país fue de 46.758 , lo que supone un $27 \%$ del total (Cuadro 18). Por regiones, fueron los canarios, con el 39\%, los que retornaron en mayor número, lo cual es lógico si tenemos en cuenta que fueron también los que emigraron en mayor cantidad, seguidos de los gallegos con el $27 \%$ de retornados.

En cuanto a las provincias gallegas, Ourense con el 36\% fue la que contó con mayor número de retornados, seguida de A Coruña con 31\% y Pontevedra con 26\%, quedando Lugo en último lugar solamente con el $6 \%$ de regresos.

\begin{tabular}{|c|c|c|}
\hline \multicolumn{3}{|c|}{ Cuadro 18. Venezuela. Retornados españoles según las provincias de destino: 1946-1958. } \\
\hline GALICIA & $1948-58$ & $\%$ \\
\hline A CORUÑA & 3.930 & 31 \\
\hline LUGO & 810 & 6 \\
\hline OURENSE & 4.464 & 36 \\
\hline PONTEVEDRA & 3.284 & 26 \\
\hline Total Galicia & 12.488 & 27 \\
\hline Total Canarias & 18.422 & 39 \\
\hline Total Espańa & 46.758 & 100 \\
\hline
\end{tabular}

Fuente: Estadísticas del Instituto Español de Emigración. (Elaboración propia).

Para un periodo más amplio, como el comprendido entre 1948-1967, el porcentaje de retorno de españoles emigrados a Venezuela fue del 46,7\% (263.829 emigrantes; 123.227 retornados). Este crecimiento es considerable y se debe a que en los años inmediatamente posteriores a la caída de la dictadura de Pérez Jiménez, en enero de 1958, aumentó el número de retornados, manteniéndose hasta mediados de la década de los ochenta en torno a un 40\%; a partir de ahí, volverá a incrementarse, debido a la creciente inestabilidad económica, social y política en que se irá sumiendo Venezuela. 


\section{Cuadro Anexo}

\begin{tabular}{|c|c|c|c|}
\hline \multicolumn{4}{|c|}{ Cuadro 19. Emigración española a Venezuela: 1946-1985. } \\
\hline Año & $\begin{array}{c}\mathrm{N}^{\circ} \text { Emigrantes a } \\
\text { Venezuela }\end{array}$ & $\begin{array}{c}\text { \% a Venezuela del total } \\
\text { a América }\end{array}$ & Total a América \\
\hline 1946 & 368 & 6,60 & 5.575 \\
\hline 1947 & 423 & 3,13 & 13.532 \\
\hline 1948 & 323 & 1,69 & 19.156 \\
\hline 1949 & 2.740 & 6,54 & 41.910 \\
\hline 1950 & 8.293 & 14,99 & 55.314 \\
\hline 1951 & 10.810 & 18,98 & 56.967 \\
\hline 1952 & 8.734 & 15,42 & 56.648 \\
\hline 1953 & 12.306 & 27,61 & 44.572 \\
\hline 1954 & 22.033 & 42,03 & 52.418 \\
\hline 1955 & 26.277 & 42,22 & 62.237 \\
\hline 1956 & 27.542 & 51,89 & 53.082 \\
\hline 1957 & 30.184 & 52,13 & 57.900 \\
\hline 1958 & 23.811 & 50,47 & 47.179 \\
\hline 1959 & 16.235 & 46,86 & 34.648 \\
\hline 1960 & 14.991 & 44,71 & 33.529 \\
\hline 1961 & 11.828 & 33,17 & 35.658 \\
\hline 1962 & 11.068 & 34,71 & 31.891 \\
\hline 1963 & 9.774 & 40,03 & 24.416 \\
\hline 1964 & 12.547 & 50,68 & 23.915 \\
\hline 1965 & 9.170 & 44,18 & 20.754 \\
\hline 1966 & 7.713 & 37,24 & 20.710 \\
\hline 1967 & 6.755 & 35,83 & 18.854 \\
\hline 1968 & 4.108 & 39,25 & 10.467 \\
\hline 1969 & 3.722 & 36,75 & 10.129 \\
\hline 1970 & 3.010 & 43,49 & 6.921 \\
\hline 1971 & 2.756 & 45,61 & 6.042 \\
\hline 1972 & 2.220 & 42,59 & 5.213 \\
\hline 1973 & 1.291 & 34,34 & 3.759 \\
\hline
\end{tabular}




\begin{tabular}{|c|c|c|c|}
\hline Año & $\begin{array}{c}\text { No Emigrantes a } \\
\text { Venezuela }\end{array}$ & $\begin{array}{c}\text { \% a Venezuela del total } \\
\text { a América }\end{array}$ & Total a América \\
\hline 1974 & 1.139 & 36,15 & 3.151 \\
\hline 1975 & 1.447 & 43,56 & 3.322 \\
\hline 1976 & 1.306 & 43,33 & 3.014 \\
\hline 1977 & 1.474 & 51,88 & 2.841 \\
\hline 1978 & 1.277 & 59,07 & 2.162 \\
\hline 1979 & 1.043 & 52,54 & 1.985 \\
\hline 1980 & 417 & 30,40 & 1372 \\
\hline 1981 & 420 & 24,48 & 1716 \\
\hline 1982 & 357 & 23,42 & 1524 \\
\hline 1983 & 168 & 13,77 & 1220 \\
\hline 1984 & 90 & 8,20 & 1097 \\
\hline 1985 & 52 & 5,31 & 979 \\
\hline $1946-85$ & 300.222 & 34,20 & 877.779 \\
\hline
\end{tabular}

Fuente: Estadísticas de Emigración (años 1946 a 1985), Ministerio de Trabajo. (Elaboración propia). 


\section{BibliografíA Y FUENTES UTILIZADAS}

Arquivo Histórico Provincial de Pontevedra (AHPPO): Documentación Comisaría Cuerpo General de Policía Puerto de Vigo, ano 1950, caixas 17-22.

Archivo Ministerio Asuntos Exteriores (AMAE): R-5692, Exp. 5-6. Informe del Cónsul General de España en Venezuela al Ministro de Asuntos Exteriores con datos e información sobre inmigración y colonia española en Venezuela. Caracas, 29 de julio de 1955 .

Archivo Ministerio Asuntos Exteriores (AMAE): R-5692, Exp. 6. Informe de la Embajada de España al Ministro de Asuntos Exteriores sobre llegadas y salidas de españoles a Venezuela durante el año 1956. Caracas, 7 de noviembre de 1957.

Berglund, S. y Hernández Calimán, H. (1985): Los de afuera: un estudio analítico del proceso migratorio en Venezuela, Caracas, Centro de Estudios de Pastoral y Asistencia Migratoria (CEPAM).

Consulado General de España en Caracas: Libros de Registro de Nacionalidad, 1950 a 1957.

Contiña, R. (1982): Gallegos en Venezuela, Caracas, Ed. Logos.

Dirección General de Estadísticas y Censos Nacionales: Anuario Estadístico de Venezuela, 1936-1994.

Dirección General de Estadísticas e Identificación y Extranjería: Cuadro Cédulas expedidas desde 1941 hasta diciembre de 1975 (extranjeros), Diex (Estadísticas 1975).

Dirección General de Estadísticas e Identificación y Extranjería: Estadística, 1975, Caracas, 1976.

Dirección General de Estadísticas e Identificación y Extranjería: Estadística, 1976, Caracas, 1977.

Dirección Nacional de Identificación y Extranjería (DIEX): Memoria y Cuenta, Caracas, 1976.

Dirección General de Trabajo: Estadísticas de Emigración. Años 1946-1951, Madrid, Ministerio de Trabajo.

Dirección General de Trabajo: Estadística del Movimiento Migratorio Transoceánico. Años 1952-1956, Madrid, Ministerio de Trabajo.

Dirección General de Trabajo: Estadísticas de Migración y Repatriación Bonificada (Movimiento Transoceánico). Años 1957-1959, Madrid, Ministerio de Trabajo.

Dirección General de Trabajo: Estadísticas de Migración Exterior. Años 1960-1967, Madrid, Ministerio de Trabajo.

Fernández Morales, M. J. (1992): La emigración española a Venezuela de 1850 a 1960, Madrid, Universidad Complutense de Madrid, Facultad de Geografía e Historia. Tesis Doctoral.

Fernández Vicente, M. J. y Kreienbrink, A. (2009): "Las relaciones del IEE con los países de ultramar", en Calvo Salgado et. al.: Historia del Instituto Español de Emigración, Ma- 
drid, Ministerio de Trabajo e Inmigración, Subdirección General de Información Administrativa y Publicaciones, pp. 231-251.

Hernández Arvelo, M. A. (1990): "El proceso de la inmigración española en Venezuela (1939-1980)”, en Boletín de la Academia Nacional de la Historia, Caracas, no 290, pp. 97-108.

Hernández Borge, J. (1992): "Últimas oleadas y cierre del proceso: Factores de atracción de los países de destino", en Historia General de la Emigración Española a Iberoamérica, Madrid, Historia 16, vol. I.

Instituto español de emigración: Emigración Española Asistida. Años 1968-1975, Madrid, Ministerio de Trabajo.

Instituto nacional de estadística: Estadísticas del Movimiento de Buques y Pasajeros por Mar con el Exterior

Instituto Galego de Estadística (1993): Movementos Migratorios de Galicia. Series estatísticas 1962-1991, Santiago de Compostela, Xunta de Galicia.

Instituto Nacional de Estadística (1950): Boletín de Estadística, Madrid, Sucesores de

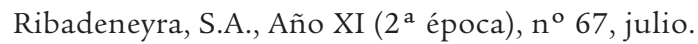

Ministerio de Fomento República de Venezuela (1964): Anuario Estadístico de Venezuela. 1957-1963. Dirección General de Estadística y Censos Nacionales, Caracas.

Ministerio de Relaciones Interiores (1959): Memoria y Cuenta del año 1958.

Palazón, S. (1995): Capital humano español y desarrollo latinoamericano. Evolución, causas y características del flujo migratorio (1882-1990), Alicante, Institut de Cultura Juan GilAlbert.

Pellegrino, A. (1989): Historia de la inmigración en Venezuela. Siglos XIX y XX, Caracas, Academia Nacional de Ciencias Económicas.

Ramírez Ribes, M. (2001): "La huella familiar de la inmigración española en Venezuela durante el siglo XX", en Jornadas de la Fundación Francisco Herrera Luque Las inmigraciones a Venezuela en el Siglo XX, Caracas.

Sánchez López, F. (1967): Movimientos migratorios de Galicia, Vigo, Faro de Vigo.

Troconis de Veracoechea, E. (1986): El proceso de la inmigración en Venezuela, Caracas, Ed. Fuentes para la Historia de la República de Venezuela.

Troconis de Veracoechea, E. (1993): Caracas, Caracas, Ed. Grijalbo. 
